\title{
PERCEPÇÃO SOCIOAMBIENTAL DO REUSO DAS ÁGUAS RESIDUÁRIAS EM CONDOMÍNIOS VERTICAIS DA CIDADE DE CAMPINA GRANDE - PB
}

\author{
F.G. A. BATISTA ${ }^{{ }^{*}}$, F. R. P. QUEIROZ ${ }^{2}$ e D. S. OLIVEIRA ${ }^{2}$ \\ ${ }^{1}$ Universidade Federal de Campina \\ ${ }^{2}$ Universidade Estadual da Paraíba \\ fabioelara@gmail.com
}

Artigo submetido em abril/2013 e aceito em dezembro/2014

DOI: 10.15628/holos.2014.1406

\section{RESUMO}

Este trabalho teve por objetivo analisar a percepção de moradores de condomínios verticais da cidade de Campina Grande na Paraíba, para as questões de perspectiva ambiental e social no que diz respeito ao reuso de águas residuárias em suas moradias. Foram selecionados quatro condomínios e doze famílias, que se disponibilizaram a participar de uma exposição e discussão sobre o tema e suas aplicabilidades e, posteriormente, a execução de questionário padrão. Como resultado pôde se constatar que as questões de ordem econômica e social foram preponderantes sobre a ambiental. As famílias, em maior representação, não se disponibilizaram par a utilização das águas residuárias devido questões de ordem ideológicas, de saúde pública e ambiental.

PALAVRAS-CHAVE: reuso, águas residuárias e condomínios verticais.

\section{PERCEPTION OF ENVIRONMENTAL WASTE WATER REUSE IN CONDOS VERTICAL CAMPINA GRANDE CITY - PB}

\section{ABSTRACT}

The purpose of this study is to analyze the residents' perception of vertical condominiums in the city of Campina Grande in the state of Paraíba, for the issues of environmental and social concerns to the reuse of wastewater in their homes. We have selected four condominiums and 12 families, who agreed to participate in an exhibition and discussion on the topic and their applicabilities and then execution a standard questionnaire. As a result, it can be seen that the issues of social and economic order are preponderant on the environmental. The families, in greater representation, didn't make themselves available to accept the use of wastewater due to ideological order concerns and public and environmental health.

KEYWORDS: reuse, wastewater and vertical condominiums. 


\section{INTRODUÇÃO}

O crescimento urbano é realidade presente e na conjuntura do desenvolvimento humano na modernidade. Seja por expectativas de emprego, estudos avançados ou no geral melhoria de vida, o ser humano busca nos centros urbanos a realização de sua satisfação pessoal e conquista dos seus anseios. Mediante a grande demanda humana nos centros urbanos, observa-se a verticalização das cidades como alternativa de oferta de moradias e organização da área habitacional nas cidades.

A preocupação cabe à disponibilidade dos recursos naturais perante o crescimento dos centros urbanos, a exemplo da cidade de Campina Grande, onde nos últimos dez anos houve considerável aumento da população e diminuição da área de acumulação do reservatório de abastecimento, no caso da água tratada. Uma viável alternativa para mitigar tal relação desproporcional, crescimento urbano e disponibilidade de água, é o reuso das águas residuárias, as quais podem ser caracterizadas como cinzas (banhos, pias e lavanderias) e negras (descargas sanitárias) para fins de uso não nobre (consumo ou utilização direta humana/animal) desde que devidamente tratadas. As águas cinza tem grande aplicabilidade para reabastecimento das bacias sanitárias e lavagens de áreas públicas. As águas negras podem ser empregadas na irrigação com o advento dos insumos orgânicos.

Experiências como as relatadas por Bdour, Hamdi e Tarawneh (2009), mostram que o crescimento das áreas urbanas de muitos países do Mediterrâneo preconiza o desenvolvimento de sistemas de saneamento ecológico, que são sustentáveis e têm a capacidade de se adaptar e expandir às necessidades da população. Os mesmos autores relatam o êxito do tratamento in locu das águas residuárias para reuso, como é o caso da agricultura e uma maciça utilização para as descargas sanitárias, evidenciando redução de custos e impactos ambientais.

Este trabalho intenciona constituir etapa para a implantação de sistemas de reuso de águas residuárias, o qual objetivou apresentar e discutir temas referentes a essas tecnologias ambientais, partindo da análise da percepção de moradores de condomínios verticais, quanto a aceitabilidade dessas tecnologias para reuso das águas residuárias.

\section{REVISÃO LITERÁRIA}

\subsection{Sustentabilidade urbana}

O desordenado crescimento dos centros urbanos remete, inevitavelmente, ao discurso das questões da sustentabilidade local. Os ambientes urbanos representam situações oportunas para realização de ideais, sejam individuais ou coletivos, nos mais diversos campos da conquista humana, para situações de ordem material, intelectual, cultural, política ou as que agreguem diversos anseios. Os centros urbanos tornam-se então promovedores de sonhos que transpassam a utopia da cognição individual, passando a determinar uma série de fatores de necessidade aos ocupantes e ao próprio ambiente físico mediante as mínimas condições básicas ao bem-estar. Partindo da premissa do crescimento populacional urbano, observa-se a crescente demanda pelos recursos naturais de ordem prioritária e geração de insumos sem destino 
adequado, os quais são agravantes emergentes do desequilíbrio ambiental, saúde pública e qualidade de vida.

Comunidades no mundo mantêm reservas de água comprometidas devido à intensa demanda pela população, aos períodos de severas secas e também à degradação e contaminação dos recursos hídricos locais. Em estudo da cidade de Campina Grande, pode-se constatar um crescimento populacional de, aproximadamente $8 \%$, o que representa uma média de 2.860 habitantes/ano (IBGE, 2010). Crescimento este é confrontado com duas variáveis consideráveis, sendo a primeira constituída pelo sistema de abastecimento de água, oriundo do Açude Epitácio Pessoa no qual ocorre processo de assoreamento e redução das matas ciliares, com agravante redução na capacidade de abastecimento de 536 milhões $\mathrm{m}^{3}$ para 436 milhões $\mathrm{m}^{3}(-18,6 \%)$, fornecidos pelo (SEMARH, 2008). A segunda é o "Bloom" na construção civil urbana e no entorno da cidade, sejam representados por condomínios verticais e horizontais, com concentração específica na zona Sul da cidade, a qual compreende bairros como Catolé, Sandra Cavalcanti e Itararé. Situações estas levam à reflexão de uma realidade local com referência global, pois se fazem em evidência o crescimento urbano e a escassez dos recursos hídricos.

\subsection{Recursos hídricos locais - gestão e conscientização}

Por o longo período do progresso histórico até a modernidade, perpassaram diversos fenômenos que congregaram com a evolução humana, porém nenhum foi mais significativo que a revolução industrial. Foi a partir desse que se fez necessária à utilização mais intensificada dos recursos naturais para as linhas de produção em detrimento à demanda do mercado consumidor. A geração de resíduos e o consumo exagerado de água nortearam os mais significativos eventos e conferências mundiais que trouxeram à sociedade os reflexos do paradigma social dominante.

O ineficaz manejo dos recursos hídricos, quando correlacionado aos altos níveis de poluição hídrica e perdas no sistema de abastecimento, desencadeia exacerbado desperdício de água pelo usuário final, ocasionando intensiva pressão nos sistemas de abastecimento de água dos centros urbanos. Para efetivar $o$ atendimento às demandas crescentes, medidas emergenciais incluindo a expansão da oferta de água (construção de reservatórios, perfuração de poços, transposição de vazões) têm sido adotadas, sendo adotados com estratégias políticas e ferramentas de poder em regiões mais carentes do país.

Os reservatórios recebem os impactos das atividades que se desenvolvem na bacia hidrográfica, onde os de natureza antrópica são geradores de maiores transtornos de ordem poluidora e degradativa. A avaliação do comportamento hidrodinâmico e dos aspectos limnológicos destes ambientes são importantes para a compreensão das dinâmicas ecológicas, econômicas e sociais, propiciando assim desenvolvimento de estratégias para o uso d'água e ações de controle da poluição. Estes procedimentos visam à preservação dos ambientes naturais e a conservação da água em quantidade e qualidade adequadas ao consumo e utilização em atividades preponderantes à manutenção socioambiental. Dessa forma, estudos qualiquantitativos permitem que instrumentos de gestão desenvolvam estratégias eficientes propiciando maior confiabilidade nas tomadas de decisão (Guimarães et al. 2005).

O abastecimento de água do município de Campina Grande é realizado pelo reservatório Epitácio Pessoa, localizado na Bacia hidrográfica do Rio Paraíba do Norte, sendo um dos maiores 
reservatórios do Estado. Conflitos quanto ao uso de suas águas vêm ocorrendo com gravidade crescente, advindos de métodos inadequados de controle fitossanitário das culturas irrigadas, da falta de planejamento que compatibilize a diversidade de utilização e emprego de processo irrigatório de elevado consumo hídrico (Machado et al. 2005). Dessa forma, pode-se convir ineficácia no processo de abastecimento, por parte do órgão responsável mediante as condições do reservatório, visto a falta de gestão integrada que garanta água de qualidade e monitorada para consumo e atividades outras a qual o recurso se faz indispensável.

Expandir a oferta de água não determina eficaz atendimento às premissas do desenvolvimento sustentável por imposição dos altos custos econômicos, sociais e ambientais. Em reformulação à tradicional ótica da expansão da oferta de água surgiu, em âmbito da gestão de recursos hídricos, faz-se emergente a adoção de medidas voltadas à redução do consumo de água pelos usuários, sem prejuízo dos atributos de higiene e conforto dos sistemas originais. Essa redução pode ser obtida através de mudanças de hábitos no uso da água ou mediante a aquisição de aparelhos ou equipamentos poupadores (PNCDA, 2000).

Com base no enfoque do gerenciamento da demanda e as crises vivenciadas pelo sistema de abastecimento de água da cidade de Campina Grande, na Paraíba, Albuquerque et al. (2004) propôs a avaliação de três medidas tecnológicas de gerenciamento da demanda (adoção de aparelhos hidrosanitários poupadores, captação de água de chuva e reuso de água). Como aparelhos hidrosanitários poupadores, foram propostos a utilização de:

- Bacia sanitária VDR: corresponde ao conjunto "bacia sanitária com caixa acoplada de volume reduzido de água por descarga";

- Chuveiros de vazão reduzida com acionamento hidromecânico;

- Torneiras de baixo consumo e dispositivos de redução de vazão: neste grupo estão as torneiras acionadas por sensor infravermelho e as torneiras com tempo de fluxo determinado; entre os dispositivos tem-se os arejadores, os automatizadores, os prolongadores e os pulverizadores.

Os mesmos autores também propuseram estudo da viabilidade da captação das águas pluviais, com objetivo de "uso primário" (consumo direto para ingestão e/ou preparação de alimentos). Os resultados da pesquisa ressaltaram, em conclusão que, as questões relacionadas à problemática do uso da água e desperdícios são conhecidas e despertam preocupação, mas há uma grande resistência quanto aplicação de investimentos ou qualquer tipo de disponibilidade que preconize mecanismo para uma redução no consumo de água, onde os atores sociais envolvidos na pesquisa apontaram para o órgãos gestor como responsável por tais investimento à nível geral.

\section{3 Águas residuárias e reuso}

São consideradas águas residuárias todas as que tenham origem no pós-uso nas mais diversas atividades, sejam industriais ou domésticas, e que tenham como destino final os tanques sépticos, reatores de digestão aeróbia e/ou anaeróbia, lagoas de estabilização, como também estações especializadas no tratamento de esgotos. As águas residuárias são consideradas problema de expressivo impacto ambiental devido à falta de tratamento adequado ao grande volume de esgoto produzido, sem o devido destino aos resíduos poluentes constituintes, como é 
o caso dos lodos que contêm uma grande carga de patógenos microrgânicos e ovos de helmintos, considerados de risco ambiental, fitossanitário e para saúde pública. O reuso das águas residuárias se faz de considerável interesse mediante o grande volume de água que poderia ser destinado adequado como para agricultura, construções prediais, lavagem de áreas públicas entre outros, que podem utilizar água de baixa qualidade, porém tratadas e monitoradas.

Segundo Finley, Barrington e Lyew (2009), o reuso de água pode ser caracterizado pelo tipo de planejamento do tratamento. Dessa forma, tem-se (I) o reuso indireto não planejado que objetiva a utilização em alguma atividade humana, oriundo de descargas no meio ambiente e novamente utilizada à jusante, em sua forma diluída, de maneira não intencional e não controlada; (II) o reuso indireto planejado ocorre quando os efluentes, depois de tratados, são descarregados de forma planejada nos corpos de águas superficiais ou subterrâneas, para incorporação à jusante, de maneira controlada, no atendimento de algum uso benéfico; (III) reuso direto planejado das águas ocorre quando os efluentes, depois de tratados, são encaminhados diretamente de seu ponto de descarga até o local do reuso, não sendo descarregados no meio ambiente. É o caso de redes paralelas, destinando-se a uso em indústria ou irrigação e (IV) a reciclagem de água que se destina ao reuso interno da água (circuito fechado), antes de sua descarga em um sistema geral de tratamento ou outro local de disposição.

O reuso de águas emblema importante procedimento que deve ser incentivado, devido constituir fonte de suprimento do recurso natural, escasso na região Nordeste devido aridez climatológica e baixas precipitações pluviométricas; proporcionar a liberação da água disponível, para outros fins, como o abastecimento humano; evitar o lançamento de efluentes de estações de tratamento de esgotos em corpos d'água, os quais, em grande parte, são intermitentes, com vazão nula durante certo período do ano; aperfeiçoar/incentivar o emprego do esgoto doméstico tratado, com advento da composição orgânica, útil às culturas irrigadas (Mota, Bezerra e Tomé, 1997).

\section{METODOLOGIA DE ESTUDO}

A pesquisa foi pautada em estrutura exploratório com participação de atores sociais, representados por moradores de condomínios verticais, com o intuito de evidenciar aspectos do grau de conhecimento e aceitabilidade do reuso das águas residuárias em suas áreas residenciais.

O estudo de campo foi realizado no bairro do Catolé, na zona Sul da cidade de Campina Grande, com visitas às condomínios verticais no período de 26 a 29 de Janeiro de 2012. Foram visitados quatro condomínio, como apresentado na Figura 1, escolhidos estes pelo grau de aceitabilidade por parte de alguns condôminos e síndicos, previamente procurados para esclarecimentos sobre o propósito do estudo. Em cada um dos conjuntos habitacionais, participaram três famílias as quais se fizeram presentes nas reuniões periódicas dos condomínios, previamente agendadas e de alcance de todos os moradores, com objetivo de tratar de questões pertinentes à coletiva, sendo oportuna a apresentação da temática de pesquisa e convite à participação nos questionamentos, onde a participação efetiva foi de três famílias por condomínio, totalizando doze participantes. 

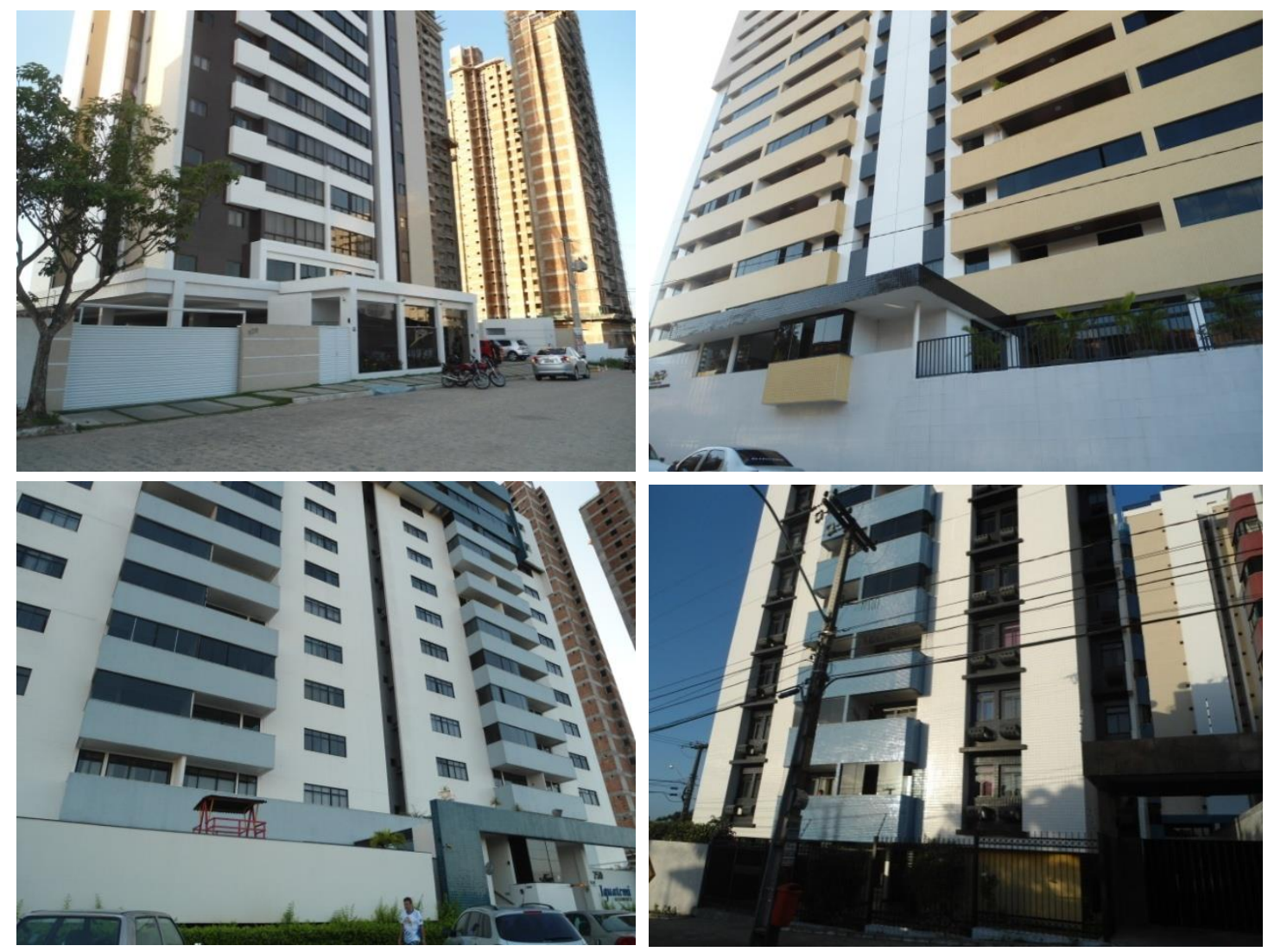

Figura 1: Condomínios verticais localizados no bairro do Catolé, zona sul da cidade de Campina Grande, selecionados para realização da pesquisa. Fotos dos autores.

A escolha da área urbana para aplicação dos questionamentos e, consequentemente, composição dos grupos amostrais derivou do acelerado processo de urbanização vertical que vem ocorrendo no bairro do Catolé, o qual apresenta mudanças consideráveis no panorama visual do ambiente físico.

Antes da aplicação do questionário foi realizada uma seção de debates sobre o tema do reuso das águas residuárias, com apresentação de conceitos e exemplos de tecnologias bem sucedidas, apresentando situações de aplicação na região Nordeste.

O questionário padrão aplicado está apresentado na Figura 2, o qual teve por objetivo alinhar os conhecimentos dos entrevistados sobre os temas abordados, porém também foi relevante a análise de conteúdos que propiciou a considerar os discursos subjetivos que embasaram uma melhor geração de dados. 


\section{QUESTIONÁRIO}

01. Faixa etária do entrevistado

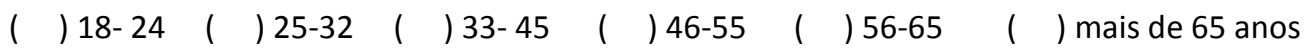

02. Número de moradores no apartamento do entrevistado

$\left(\begin{array}{lllllllll}1) 1-2 & (\quad) 3-4 & (\quad)-6 & (\quad)-8 & (\quad) \text { mais de } 9\end{array}\right.$

03. Tempo que reside no condomínio

( ) 1 ano ( ) 2-3 anos ( ) 4-5 anos ( ) 6-7 anos ( ) mais de 8 anos

04. Qual é periodicidade da ocorrência de reuniões e como se faz a participação dos condôminos para discussão e esclarecimentos de assuntos de interesse comum?

05. Existe algum mecanismo de reserva de água no condomínio?

06. Seu condomínio tem algum sistema de aproveitamento/segregação das águas residuárias?

07. Você concorda com o aproveitamento das águas cinzas (banho e pia do banheiro), devidamente tratada, para a irrigação das áreas verdes e lavagens das áreas social?

08. Você concorda com o aproveitamento das águas negras (descargas sanitárias), devidamente tratadas, para a irrigação das áreas verdes?

09. Você concordaria, em coletividade, no investimento de adaptações hidráulicas que propiciassem o devido aproveitamento das águas residuárias, sabendo da economia do recurso natural, monetário e da devida aplicabilidade?

10. Tem alguma preocupação quanto a relação: crescimento populacional urbano e a baixa disponibilidade e reservação de água para a produção de alimentos o consumo humano?

Figura 2. Questionário padrão aplicado

A análise das entrevistas consistiu na avaliação do conhecimento e aceitabilidade dos entrevistados em relação às propostas e ideias apresentadas. Foram analisados os seguintes critérios de avaliação, segundo trabalho realizados por Albuquerque et al. (2004):

I. Aceitabilidade geral, referindo-se às alternativas tecnológicas apresentadas e discutidas (independente dos relativos desafios para implementação e manutenção). Este critério é analisado a partir dos questionamentos 6, 7 e 8 .

II. Aceitabilidade econômica, correspondendo à perspectiva de custos. Este critério é analisado no questionamento 9.

III. Aceitabilidade ambiental, referindo-se à implantação de alternativas pelos condôminos sob a ótica ambiental, ou seja, escolha da alternativa de acordo com o benefício ambiental que esta possa vir a oferecer (redução de consumo de água). Este critério é analisado no questionamento 10 . 


\section{RESULTADOS E DISCUSSÃO}

Os resultados das entrevistas foram organizados em gráficos mediante arranjo de grupos e respostas, sendo possível a elaboração conjugada e individualizada, por questões aplicadas no questionário padrão. 0 grupo amostral total foi composto por 12 família participantes, sendo este o referencia para a elaboração das figuras que seguem.

O conjunto inicial de resultados demostrou o perfil das famílias participantes quanto à composição etária, familiar e organizacional quanto ao condomínio vertical o qual residem. Os resultados estão organizados no conjunto gráfico da Figura 3.
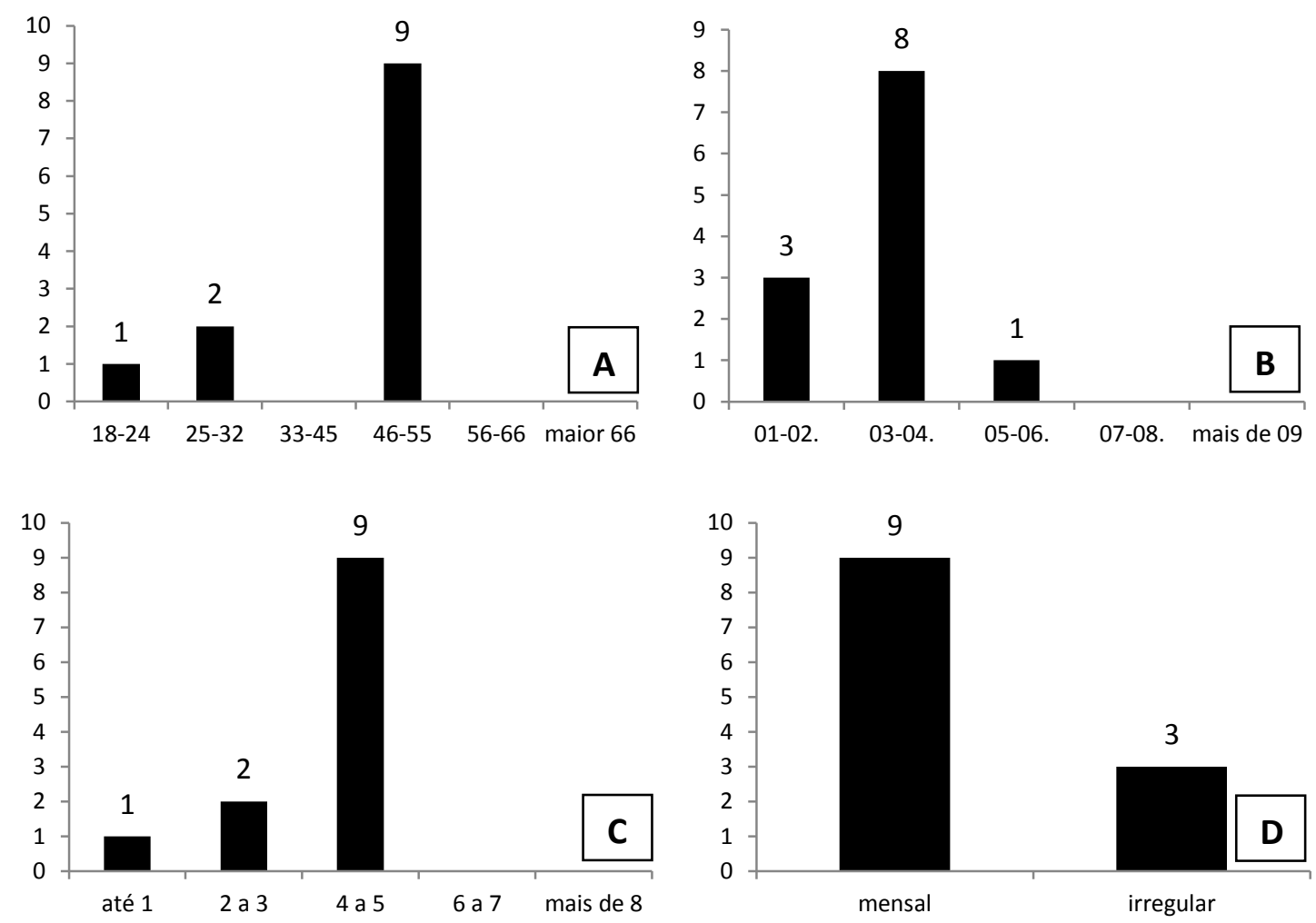

Figura 3. Resultado dos questionamentos 1, 2, 3 e 4 do questionário padrão: A - Composição da faixa etária dos entrevistados; B - Número de residentes no apartamento do entrevistado; C - Tempo de residência no condomínio (anos) e D - Organização das reuniões entre os condôminos.

A partir dos dados obtidos do questionamento aplicado, foi possível estimar o perfil dos entrevistados, em relação à faixa etária, onde $75 \%$ apresentaram idade entre 46 a 55 anos, com famílias constituídas por até quatro ocupantes e tempo de residência de mais de quatro anos. A menor parcela de entrevistados foi determinada com idade entre os 25 e 32 anos, sendo residente apenas um ocupante em período equivalente de dois anos.

A faixa etária dos participantes faz alusão à constituição familiar, sendo possível notar que a estabilidade no tempo de residência, reflete num padrão organizacional dos entrevistados para perfil de ordem socioeconômica privilegiado, em detrimento ao padrão desigual no próprio bairro. 
Quando questionados sobre a periodicidade de reuniões de condôminos, Figura 3.D, a maioria (75\%) relatou a ocorrência mensal, onde são debatidos assuntos de interesse coletivo e discussões sobre investimentos e despesas. Vale ressaltar que foi indagado por um dos entrevistados que:

“...as reuniões são a grande estratégia para a manutenção das boas relações entre os vizinhos e as responsabilidades que são cabíveis a todos...".

Os demais questionados, que somaram $25 \%$, não expressaram com exatidão os períodos de ocorrência das reuniões coletivas, apresentando incerteza em mencionar as realizações alegando certo desinteresse pelo assunto, chegando a indicar reuniões semanais, e logo após rasuravam ou retificavam oralmente que eram quinzenais, sendo notório o grau de incerteza quanto ao questionamento.

Os questionamentos sequentes propostos aos condôminos objetivaram a discussão dos aspectos ambientais da pesquisa, quanto ao reuso das águas residuárias. Mediante a subjetividade das respostas, as mesmas foram organizadas em padrão de aceitabilidade, não compondo a construção gráfica as opiniões paralelas. As respostas aos seis últimos questionamentos compõem a Figura 4, ordenada de acordo com a sequência de perguntas do questionário aplicado.

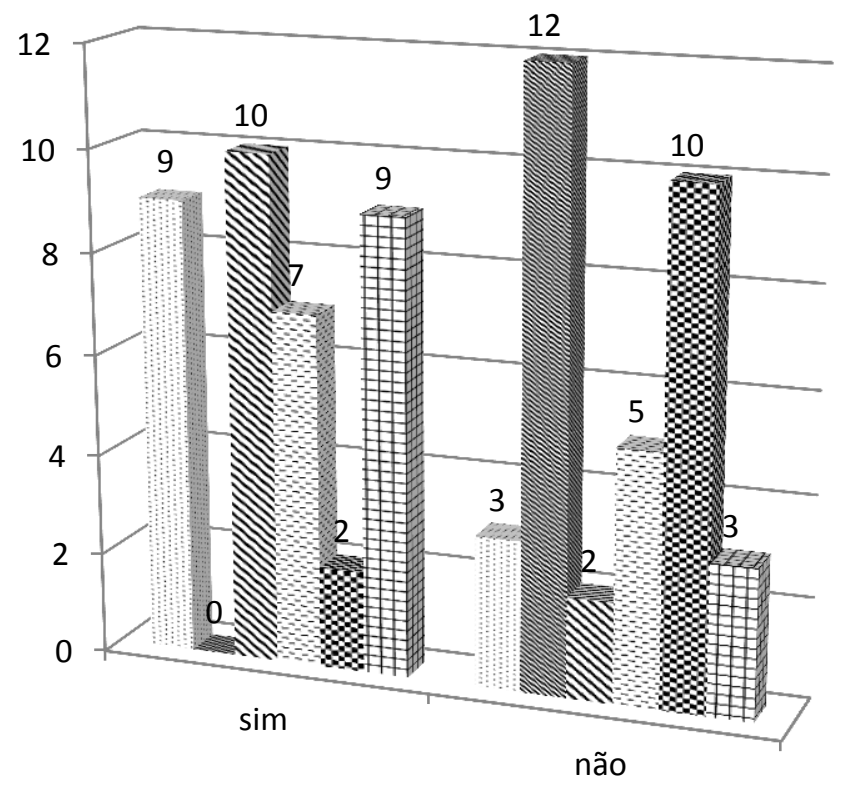

5. mecanismo de reserva de água

乙6. sistema de aproveitamento de água

7. concorda com o aproveitamento das águas cinzas

- 8. concorda com o aproveitamento das águas negras

7. concordaria com investimentos para adaptações hidráulicas

- 10. responsabilidade socioambiental

Figura 4. Respostas aos questionamentos socioambientais.

Quanto à existência de algum mecanismo de reservação e aproveitamento de águas, a maioria dos entrevistados (75\%) apontou a existência de caixas d'água de distribuição para os apartamentos, localizadas na cobertura do condomínio. Tal situação foi apontada com concisão e clareza. Os demais participantes afirmaram a existência de reservação, mas não apontaram o tipo com veemência, supondo caixa d'água convencional. Os entrevistados que não souberam com exatidão indicar algum mecanismo de reservação foram os que apresentaram menor tempo 
de moradia nos condôminos, aparentando serem menos envolvidos com as questões de ordem coletiva.

Após as discussões levadas ao grupo de condôminos participantes da pesquisa a qual apresentou estratégias alternativas e tecnologias para o reuso das águas residuárias, foi unanime a indicação da inexistência de qualquer forma e/ou mecanismo de aproveitamento das águas residuárias em suas moradias (questão 6), onde entre as diversas opiniões elucidadas em debate com os entrevistados, faz-se importante apontar situações de certo grau de sensibilização:
"...o que é bom nunca é divulgado, e no final somos vítimas da nossa ignorância".
“...é importante pensar que damos descarga com água tratada para o consumo, quando poderíamos aproveitar água do banho para tal..."

As respostas aos questionamentos 7 e 8 geraram uma reflexão mais dimensionada ao reuso das águas residuárias, visto 10 dos entrevistados acatarem o reuso de águas cinzas (oriundas de pias e do banho) para usos não diretos, inclusive nas suas descargas sanitárias, apresentando, nos debates propostos, opinião formada e entendimento para com o potencial de emprego dessa fonte hídrica nas operações do cotidiano domiciliar individual sanitário e coletivo. Os não foram a favor das ideias apresentadas justificaram, ideologicamente, por questionamentos para possíveis riscos à saúde, mesmo depois de apresentados e discutidos estratégias de reuso bem sucedidas e isentas de perigo à saúde e/ou ambiência. Porém, quando questionados sobre o reuso das águas negras devidamente tratadas, a adesão à ideia foi de apenas 7 dos participantes, os quais também acataram o reuso de águas cinzas. Tal questão propiciou o mais significativo e prolongado debate entre os pesquisados, visto o tocante às questões da saúde e empregabilidade dessas águas, visto a pouca dimensão e expressão das áreas verdes dos condomínios verticais participantes, sendo a irrigação a mais relevante forma de reuso dessas águas residuárias.

A implantação de sistema de reuso de água cinza em condomínio residencial reduz o consumo de água potável para usos menos nobres, que submetido a processos de tratamentos com tecnologias de eficiência controlada não alteraram o consumo de energia elétrica do condomínio e ainda contribui para o planejamento e a gestão sustentável dos recursos hídricos das cidades (BRAGA, 2009).

Segundo simulação orçamentária descrita por Santos, Araujo e Alexandria Monteiro (2012), o custo para a adaptação residencial que objetive a segregação, tratamento adequado e emprego das águas cinza em descargas sanitária, fica em torno de $\mathrm{R} \$ 29.533,80$ (vinte e nove mil, quinhentos e trinta e três reais e oitenta centavos), incluídos matérias e mão de obra. Foi possível constatar, de acordo com hipóteses e modelos de aplicação e investimentos, em debate participativo, que os entrevistados que expressaram não interesse quanto à utilização das águas residuárias, conseguiram persuadir os demais, pondo em evidência situações extremistas quanto a custos, riscos de ordem da saúde e bem estar de suas moradias.

Visto as considerações a respeito dos questionamentos 6,7 e 8, pode-se identificar que a aceitabilidade geral dos participantes quanto às tecnologias e estratégias apresentadas para 0 
reuso das águas residuárias segregadas foi a baixo da expectativa, tendo sido apenas possível constatar 2 participantes que se mantiveram disponíveis às propostas apresentadas e debatidas.

Analisando o sistema de reuso das águas cinza implantado Condomínio Residencial Dona Júlia, Itajubá, Minas Gerais, Braga (2009) constatou redução do consumo de água potável em $34,20 \%$, pela demanda diária de vazão que abastece o vaso sanitário, as áreas de irrigação e as áreas de limpeza de pátios e garagens. A adoção do reuso de água cinza em condomínios residenciais poderia resultar uma economia de 58,82 litros por pessoa por dia, perfazendo um total de 41.309,24 litros ao ano, projeção esta em nível teórico.

Questionados sobre a disponibilidade para investimentos que objetivariam, por adaptações hidráulicas, o reuso das águas residuárias (questão 9), 10 dos entrevistados se indisponibilizaram a qualquer custo para tais fins, e os demais descreveram que fariam um estudo quanto aos investimentos e retorno para avaliação, com mais cautela, da viabilidade e possíveis resultados. Contudo, foi ressaltado que o mais exequível seria investir no reuso das águas cinza para descargas sanitárias e limpeza das áreas comuns dos condomínios, sendo estas as possibilidades mais cabíveis à adaptações nos condomínios.

Estudos sobre investimentos em tecnologias ambientais demonstraram que pode haver redução real de até $22 \%$ no consumo de água potável, e caso a implantação de tecnologias de reaproveitamento de águas cinza se façam em paralelo à construção do condomínio, o acréscimo de investimento é de 1,54\%, segundo estudo de Gonçalves, Simões e Wanke (2011), em observação à edificação do Edifício Royal Blue, na cidade de Vitória, Espírito Santo. O tempo de retorno do investimento pode variar de 5 a 8,5 anos, cumprindo assim com as questões de ordem socioambiental em prol da sustentabilidade local.

Pode-se constatar que a aceitabilidade dos projetos teve por preponderante a questão econômica, visto recusa de dez dos entrevistados para investimentos em suas moradias para o reuso de águas de baixa qualidade, não gerando qualquer expectativa de orçamento para adaptações aos condôminos, com interesse coletivo e inclusivo aos moradores não participantes.

Quando questionados sobre o crescimento urbanos e a disponibilidade de água para o futuro (questão 10), 9 dos entrevistados apresentaram certa preocupação com panorama urbanístico e se permitiram a reflexão e preocupação com a escassez e distribuição de água. Os demais ressaltaram não haver preocupações de ordem temporal visto a construção de outras barragens e processos de transposição que objetivam ampliar a oferta de água para a população, transparecendo preocupação "descomprometida" visto não concordarem com a desproporcionalidade entre o crescimento urbano e a demanda de água, valendo observar alguns comentários:

“...o bairro já não é mais o mesmo, pois até os ventos estão mudados. Não acredito em um colapso da água mas apenas com a violência..."

“...o açude que nos abastece já passou por fortes pressões e estamos prestes a ser abastecidos por outras barragens..."

“...a cidade só apresenta o crescimento que observamos por dar suporte para o mesmo, pois as condições de vida vão se tornando cada vez melhores..." 
Mediante os relatos descritos, faz-se possível perceber que a aceitabilidade para as questões de ordem ambiental são muito instáveis, partindo de pressupostos e preconceitos estabelecidos por parte dos entrevistados, pois pensar que o crescimento urbano e a demanda de água não preocupam visto a construção de outros reservatórios que ofertem água significa em equidade urbana, pode ser enganosa devido não considerar as consequências do estabelecimento desse novo reservatório, tratamento adequado da água, distribuição e muitas outras questões na ordem do saneamento ambiental. É de extrema importância a realização/promoção de debate e palestras que elucidem aos moradores, seja de condomínios ou de residências individualizadas, questões sobre a educação ambiental e estudos para a melhoria local em detrimento aos impactos ambientais iminentes em nossa região, sejam de ordem climatológicos, hídricos, urbanos, de saúde pública coletiva e ideológica. É importante considerar que viver em condomínios representa viver em coletividade, visto cada ação ser desencadeadora do bem comum social, podendo também mediar situações adversas.

\section{CONCLUSÃO}

A percepção socioambiental de um grupo amostral de moradores de condomínios verticais da cidade de Campina Grande, Paraíba, mediante debate que elucidou o emprego de estratégias e tecnologia para o reuso das águas residuárias segregadas, em panorama do crescimento urbano e aumento na demanda de água, obteve baixa aceitabilidade devido questões de ordem econômica e ideológica. A partir de questionário aplicado e debate realizado em reunião de condomínio, os atores sociais participantes não se dispuseram a aplicar e/ou investir na reutilização dessas águas em seus apartamentos ou em áreas coletivas, seja em nível de simulação ou projeção, devido desconhecimento do tema ou levantamento de preconceitos sobre a aplicabilidade dos resíduos pós-tratados.

Este posicionamento evidencia fragilidade e uma concepção invariável dos moradores de condomínios verticais para questões da responsabilidade socioambiental, pois o reuso de águas de baixa qualidade perpassa solução ou estratégia de ordem local, visto o dimensionamento dos problemas ocasionados pelo esgotamento, baixa condição sanitária e de distribuição de águas, sendo uma abordagem estratégica para sustentabilidade ambiental.

Faz-se sugestivo que futuras pesquisas busquem os mesmos atores sociais para elucidar outras problemáticas de ordem ambiental, pautadas no debate e possibilidades de planos de ação local para mitigação dos mesmos, com intuito de verificar o nível de percepção socioambiental e participativa, visto as responsabilidades cabíveis a cada cidadão em relação ao ambiente físico que altera, ocupa e polui.

\section{REFERÊNCIAS BIBLIOGRÁFICAS}

1. AlBUQUERQUE, T.M.A; RIBEIRO, M.M.R.; GUEDES, M.J.F; MOTTA, M.L e ALBUQUERQUE, F.S. Avaliação de alternativas tecnológicas para redução do consumo de água. IV SEREA Seminário Hispano-Brasileiro sobre Sistemas de Abastecimento Urbano de Água. João Pessoa (Brasil), Nov. 2004.

2. BDOUR, A.; HAMDI, M. and TARAWNEH, Z. Perspectives on Sustainable Wastewater 
Treatment Technologies and Reuse Options in the Urban Areas of the Mediterranean Region. Desalination, v.237 (1-3), 162-174. 2009.

3. BRAGA, E.D.; Estudos de reuso de água em condomínio s residenciais. Dissertação de mestrado; UNIFEI. Itajubá, 145p., 2009.

4. GUIMARÃES, A.O.; MELO, A.D.; CEBAllOS B.S.O.; GALVÃO, C. O. \& RIBEIRO, M.M.R. Aspectos da gestão do Açude Epitácio Pessoa (PB) e variação da qualidade de água. 23 Congresso Brasileiro de Engenharia Sanitária e Ambiental. Campo Grande/MS - Setembro de 2005.

5. IBGE - INSTITUTO BRASILEIRO DE GEOGRAFIA E ESTATÍstICA. Contagem da População segundo os Municípios da Paraíba - 2010. Disponível em:http://www.ibge.gov.br. Acesso em: 05 fev 2012.

6. FINLEY S., BARRINGTON S. e LYEW D. Reuse of domestic greywater for the irrigation of food crops. Water, Air, and Soil Pollution, vol. 199, no. 1-4, pp. 235-245, 2009.

7. GONÇALVES, R. F; SIMÕES, G.M.S; WANKE, R. Reuso de águas cinzas em edificações urbanas estudo de caso em Vitória (ES) e Macaé (RJ). Revista AIDIS, v. 3, n. 1, p. 120-131, 2011.

8. PNCDA - PROGRAMA NACIONAL DE COMBATE AO DESPERDÍCIO DE ÁGUA. Secretaria de Política Urbana. Disponível em: <http://www.pncda.gov.br/.> Acesso em: 07 fev 2012.

9. MACHADO, T.T.V.; GADELHA, C.L.M.; JUNIOR, W.R. da S.; DINIZ, F.E.G; COLARES, D.A. \& NEVES, A.F.J.F. Avaliação preliminar da presença de chumbo e cromo em mananciais do estado da Paraíba, utilizados em sistemas urbanos de abastecimento de água. 23을 Congresso Brasileiro de Engenharia Sanitária e Ambiental. Campo Grande/MS - Setembro de 2005.

10. MOTA, S.; BEZERRA, F. C.; TOMÉ, L. M. Avaliação do desempenho de culturas irrigadas com esgotos tratados. 19 Congresso Brasileiro de Engenharia Sanitária e Ambiental. Anais... Foz do Iguaçu: Associação Brasileira de Engenharia Sanitária e Ambiental, 1997. p.20-26.

11. SEMARH - Paraíba. Levantamento Batimétrico do Açude Epitácio Pessoa - Boqueirão/ PB. Secretaria Extraordinária do Meio Ambiente, dos Recursos Hídricos e Minerais, 2008. Disponível em: http://www.paraiba.pb.gov.br/15224/semarh. Acesso em 06 fev 2012.

12. SANTOS, M.L.G.; ARAUJO, E.S.; ALEXANDRIA MONTEIRO, A.S. Reaproveitamento da água do chuveiro e lavatório para reutilização na descarga do vaso sanitário. In: VII CONNEPICongresso Norte Nordeste de Pesquisa e Inovação. 2012. 